\title{
Manejos de cobertura, mecanismos sulcadores e velocidades de operação sobre a semeadura direta da cultura do milho
}

\author{
Emerson Trogello ( $\left.{ }^{*}\right)$; Alcir José Modolo $\left({ }^{2}\right)$; Marina Scarsi (2); Rivanildo Dallacort ( $\left.{ }^{3}\right)$ \\ (') Universidade Federal de Viçosa (UFV), Departamento de Fitotecnia, Campus Universitário, 36570 000, Viçosa (MG), Brasil. \\ (2) Universidade Tecnológica Federal do Paraná (UTFPR), Coordenação de Agronomia, Via do Conhecimento, Km 1, 85503-390, Pato \\ Branco (PR), Brasil. \\ (3) Universidade do Estado de Mato Grosso (UNEMAT), Curso de Agronomia, Rodovia MT 358, km 7, 78300-000, Tangará da Serra \\ (MT), Brasil. \\ (*) Autor correspondente: emerson.trogello@ufv.br
}

Recebido: 4/abr./2012; Aceito: 12/mar./2013

\begin{abstract}
Resumo
A palhada de cobertura residual representa o grande diferencial do sistema de semeadura direta, propiciando melhorias nas condições biológicas, químicas e físicas do solo, em contrapartida esta matéria seca residual pode implicar em dificuldades no processo de semeadura, necessitando por vezes de um manejo deste resíduo. O presente trabalho teve por objetivo avaliar o desenvolvimento e produtividade da cultura do milho submetido a diferentes métodos de manejo de palhada, mecanismos sulcadores e velocidades de operação. Utilizou-se o delineamento em blocos ao acaso com parcelas subsubdivididas, composto por 16 tratamentos e quatro repetições, totalizando 64 unidades experimentais. Os tratamentos foram compostos pela combinação entre quatro manejos de palhada (palha gradeada, rolada, triturada e dessecada), dois mecanismos sulcadores (disco duplo e haste sulcadora) e duas velocidades de semeadura (4,5 e 7,0 km h-1). Avaliou-se a profundidade de deposição de sementes, área de solo mobilizada, uniformidade de distribuição de sementes, estande inicial de plantas, número de fileiras por espiga, número de grãos por fileira, massa de mil grãos e produtividade da cultura. Os dados obtidos foram submetidos às análises de variância e havendo diferenças significativas, as médias foram comparadas pelo teste de Tukey, a 5\% de significância. A velocidade de operação de $7,0 \mathrm{~km} \mathrm{~h}^{-1}$ apresentou valores de espaçamentos falhos e duplos mais elevados. Os tratamentos empregados não influenciaram os componentes de rendimento da cultura, bem como não se observou diferenças significativas para a produtividade média da cultura de milho.
\end{abstract}

Palavras-chave: semeadura direta, Zea mays, Avena strigosa, qualidade de semeadura, produtividade da cultura.

\section{Covering management, furrowing mechanisms and working speed over direct seeding of corn cultivation}

\section{Abstract}

The stubble covering left over represents the biggest difference of the direct seeding cultivation, providing improvement on biological, chemical and physical soil conditions. Nevertheless, the dry matter remaining may difficult the seeding process, demanding additional management of covering. The aim of this study was to evaluate the development and yield of corn cultivation submitted to different methods of stubble management, furrowing machinery and working speed. A block outlining was used at random with sub-divided lots consisting of 16 treatments and four repetitions, totalizing 64 experimental unities. The treatments consisted of a combination between four stubble managements (harrowed, rolled, grinded and desiccated stubble), two furrowing machines (double disc and furrowing shank) and two seeding velocities (4.5 e $7.0 \mathrm{~km} \mathrm{~h}^{-1}$ ). Deposition depth was evaluated, as well as mobilized soil area, eeding distribution, initial plant stand, rows per corn spike, grain per row, weight of thousand grains and crop yield. The data were submitted to the analysis of variance and since there were significant differences, the averages were compared by the Tukey test, at 5\% of significance. The working speed of $7.0 \mathrm{~km} \mathrm{~h} \mathrm{~h}^{-1}$ increased faulty and double spacing. The method proposed herein did not affect crop yield and its components.

Key words: direct seeding, Zea mays, Avena strigosa, seeding quality, crop yield. 


\section{INTRODUÇÃO}

O sistema de semeadura direta preconiza a realização da semeadura em solo sem preparo prévio, visando à obtenção de menor mobilização do solo e a redução do tráfego de máquinas sobre a área de semeadura. Este sistema se baseia na busca por uma maior manutençáo de material vegetal sobre a superfície do solo (FurLani et al., 2007; ANDRADE et al., 2009), proporcionando modificaçóes nas propriedades químicas (FAlleiro et al., 2003), físicas (Falleiro et al., 2003; Luciano et al., 2010) e biológicas do solo (CARneiro et al., 2009) e tendendo a conservação por períodos mais prolongados da água e da matéria orgânica.

Torna-se necessário um manejo especial para fracionar, reposicionar e/ou colocar o material vegetal em contato com a superfície do solo. O manejo das plantas de cobertura pode ser efetuado por métodos mecânicos, dentre os quais destaca-se a roçadora, a grade niveladora, o rolo faca e o triturador de palhas, e métodos químicos que dá-se basicamente pela utilização de herbicidas de ação total, isto é, herbicidas que não possuem seletividade, eliminando toda a vegetação presente (BRANQUINHO et al., 2004).

Este manejo de cobertura do solo afeta diretamente o processo de semeadura das culturas, sendo os mecanismos sulcadores ferramentas altamente influenciadas por estes manejos. Segundo Siqueira e Casão Junior (2004) os sulcos de semeadura devem ser abertos de forma a proporcionar economia de potência e ao mesmo tempo, garantir a adequada posição do fertilizante e das sementes e o bom desenvolvimento das plantas. Os mesmos autores ainda ressaltam que, a abertura do sulco é feita em sua maioria por mecanismos sulcadores do tipo disco duplo desencontrado e haste sulcadora, e o desempenho dos mesmos é influenciado pelo seu projeto, pelas características do solo, pela pressão exercida pela semeadora-adubadora, quantidade de palha, profundidade de atuação e velocidade de deslocamento (Germino e Benez, 2006).

Além dos fatores manejo de palhada e mecanismos sulcadores, a velocidade de operaçáo é outro fator que assume grande importância na operação de semeadura, uma vez que, a mesma pode influenciar na qualidade de abertura e fechamento de sulco, profundidade de deposição de sementes e uniformidade de distribuição das mesmas ao longo da linha de semeadura. A velocidade de operação pode afetar o estabelecimento, os componentes de produtividade e consequentemente a produtividade média da cultura (GARCia et al., 2006), uma vez que, este fator afeta a patinagem dos rodados; capacidade de campo; velocidade do mecanismo dosador; distância, profundidade e exposição de sementes; ocorrência de duplos e falhos; e danos mecânicos (Mello et al., 2007; Pinheiro Neto et al., 2008; Garcia et al., 2011).

Diante do exposto e das variáveis respostas de culturas ao emprego da semeadura em condições de elevada cobertura de palhada sobre o solo, o presente trabalho objetivou avaliar a influência de diferentes manejos de palhada de cobertura de aveia, mecanismos sulcadores e velocidades de operação sobre parâmetros da qualidade de semeadura, e componentes de produtividade da cultura do milho.

\section{MATERIAL E MÉTODOS}

O experimento foi conduzido em área experimental na regiāo sudoeste do Estado do Paraná (26 16'36"S; $52^{\circ} 41^{\prime 2} 20^{\prime \prime}$ ). O solo é caracterizado como Latossolo Vermelho distroférrico, com textura muito argilosa $(77,4 \%$ de argila, $20,3 \%$ de areia e $2,3 \%$ de silte) e $56,96 \mathrm{~g} \mathrm{dm}^{-3}$ de matéria orgânica. O clima é subtropical úmido do tipo (Cfa), conforme classificação de Köppen, com uma altitude média de $760 \mathrm{~m}$ e declividade entre 0 e 3\%. A área de implantação do experimento tem sido manejada com sistema de semeadura direta por três anos consecutivos, semeando-se a cultura da aveia no período de inverno e milho/soja no período de verão.

O delineamento experimental utilizado foi o de blocos casualizados no esquema de parcelas subsubdivididas com quatro repetiçôes. As parcelas constituíram os quatro métodos de manejo de palhada (palha gradeada, rolada, triturada e dessecada), as subparcelas os dois mecanismos sulcadores (disco duplo desencontrado e haste sulcadora) e as subsubparcelas as duas velocidades de operação $(4,5$ e $7,0 \mathrm{~km} \mathrm{~h}^{-1}$ ), totalizando 64 unidades experimentais. As parcelas principais tiveram dimensōes de $296 \mathrm{~m}^{2}$ $(14,8 \times 20 \mathrm{~m})$, as subparcelas de $148 \mathrm{~m}^{2}(7,4 \times 20 \mathrm{~m})$ e as subsubparcelas de $74 \mathrm{~m}^{2}(3,7 \times 20 \mathrm{~m})$. Utilizou-se um espaçamento de $10 \mathrm{~m}$ entre cada bloco, utilizados para manobra e estabilização da velocidade de trabalho do conjunto motomecanizado.

Conduziu-se a semeadora-adubadora em duas velocidades de operaçãoo $\left(4,5\right.$ e 7,0 $\left.\mathrm{km} \mathrm{h}^{-1}\right)$, as quais representam limiares de mínima e máxima velocidade para semeadura da cultura do milho. Utilizaram-se dois mecanismos sulcadores: haste sulcadora com ponteira de $14,76 \mathrm{~mm}$ de largura, ângulo de ataque de $30^{\circ}$ e altura de $0,45 \mathrm{~m}$ (Figura 1a); disco duplo desencontrado com $381 \mathrm{~mm}$ (15”) de diâmetro (Figura 1b).

Os diferentes manejos de palhada foram obtidos mediante utilização de três manejos mecânicos (palha gradeada, rolada e triturada) e um manejo químico da cobertura (palha dessecada). Os diferentes tratamentos foram empregados sobre a cultura de cobertura da aveia preta (Avena strigosa Schreb), a qual foi semeada no inicio do período de inverno e se encontrava em pleno período de florescimento, apresentando seu maior acúmulo de matéria seca, com média residual de $7759 \mathrm{~kg} \mathrm{ha}^{-1}$, mensurada a partir de amostragem aleatória em área de $0,25 \mathrm{~m}^{2} \mathrm{em}$ todas as unidades experimentais. 
O manejo de palha gradeada foi realizado com o auxilio de uma grade niveladora marca Baldan, modelo NV de dupla açáo, composta de 28 discos espaçados $0,175 \mathrm{~m}$ entre si, peso aproximado de $750 \mathrm{~kg}$ e largura de trabalho de $2,35 \mathrm{~m}$, a mesma operou em regime semi-aberta, mobilizando mínima quantidade de solo. O manejo de palhada triturada foi realizado com um triturador marca Jan/Triton, modelo 1800, com largura de corte de 1,8 m e regulado a uma altura de corte de $0,07 \mathrm{~m}$. O manejo de palhada rolada foi realizado com um rolo faca da marca Triton preenchido com meia capacidade de água e com largura de trabalho de 1,2 m. Por fim, o manejo de palhada dessecada foi realizado utilizando-se um pulverizador da marca Jacto modelo AM-12, barra com $12 \mathrm{~m}$ de comprimento, tanque com capacidade para $600 \mathrm{~L}, 24$ pontas do tipo leque, espaçadas $0,50 \mathrm{~m}$ entre si. No tratamento de palhada dessecada utilizou-se o herbicida Glifosate Atanor, na dosagem de 2,5 $\mathrm{L} \mathrm{ha}^{-1}$.

A semeadura do milho foi realizada 15 dias após os manejos da palhada de cobertura (28 de outubro de 2010), utilizando-se o híbrido simples Dekalb 240 YG, semeado em espaçamento de $0,80 \mathrm{~m}$ entre fileiras e com 70.000 sementes ha ${ }^{-1}$ ou 5,6 sementes $\mathrm{m}^{-1}$, compondo o estande de plantas. A adubação da área foi composta por $300 \mathrm{~kg} \mathrm{ha}^{-1} \mathrm{da}$ formulação NPK 08-20-20 na semeadura e $150 \mathrm{~kg}$ de $\mathrm{N} \mathrm{ha}^{-1} \mathrm{em}$ cobertura, fracionada em duas aplicaçôes, realizada conforme recomendação da CQFs (2004) objetivando uma produtividade media de $10000 \mathrm{~kg} \mathrm{ha}^{-1}$.

Utilizou-se uma semeadora-adubadora de precisão para semeadura direta, marca Vence Tudo, modelo SA 14600 composta de cinco linhas, espaçadas $0,80 \mathrm{~m}$. Utilizou-se disco horizontal perfurado Apollo n. ${ }^{\circ} 7$ de 28 furos na cor laranja e um anel da Agrodisco n. ${ }^{\circ}$ 001, do tipo rebaixado na cor verde. Como fonte de potência, utilizou-se um trator New Holland, modelo TL75E, 4x2 TDA (Tração Dianteira Auxiliar), com potência máxima de $57,4 \mathrm{~kW}(78 \mathrm{cv}$.) a $2.400 \mathrm{rpm}$.

Após a semeadura da cultura do milho, realizou-se nas três linhas centrais de semeadura as avaliaçôes das seguintes variáveis: profundidade de deposição das sementes, área de solo mobilizada, marcha de emergência, uniformidade de distribuição de sementes, estande inicial de plantas, componentes de produtividade da cultura.

A profundidade de deposição das sementes de milho foi realizada em dez plantas por linha de semeadura, sendo determinada quando as plântulas estavam com 0,05 m de altura, cortando-se a parte aérea da planta rente ao solo e, com uma espátula, retirando a parte enterrada no solo e medindo o comprimento do epicótilo até a semente.

A área de solo mobilizada no sulco de semeadura foi avaliada com o auxilio de um perfilômetro construído em madeira (Figura 2), com réguas verticais graduadas em centímetros, dispostas a cada $0,02 \mathrm{~m}$ no sentido transversal à linha de semeadura. O cálculo da área de solo mobilizada foi realizado por meio de planimetria, seguindo a equação:

$A m=\left(P_{N}-P_{F}\right)^{*} e$

Em que:

Am: área mobilizada no sulco de semeadura, $\mathrm{cm}^{2}$; $P_{N}$ : valor do perfil da superfície natural do solo (pré-semeadura) para cada ponto do perfilômetro, $\mathrm{cm}$;

$P_{F}$ : valor do perfil da superfície final do solo (pós-semeadura) para cada ponto do perfilômetro, cm; $e$ : espaçamento entre réguas verticais, $\mathrm{cm}$.

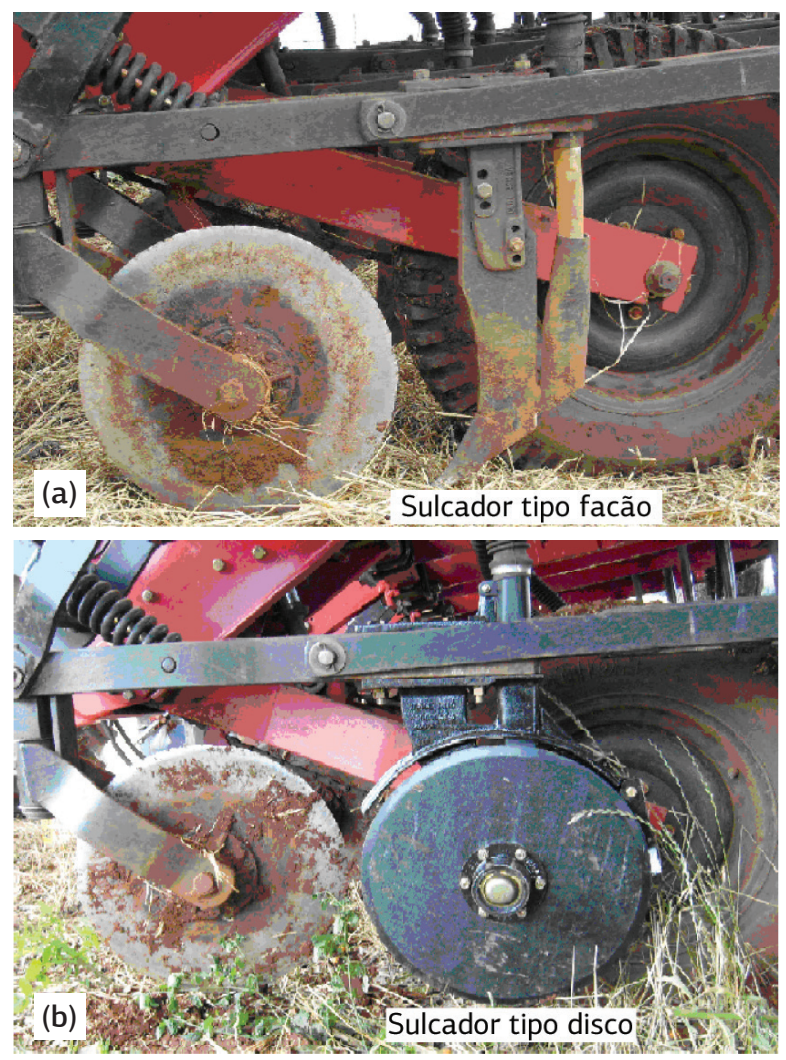

Figura 1. Mecanismos sulcadores utilizados: haste sulcadora (a) e disco duplo desencontrado (b).

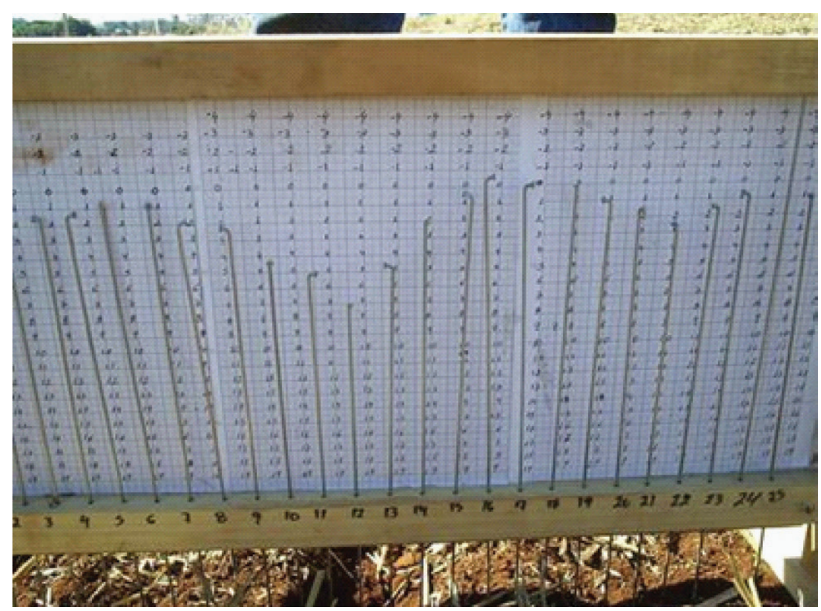

Figura 2. Perfilômetro em madeira utilizado para medida de área de solo mobilizado. 
A marcha de emergência foi determinada por meio de contagens diárias em $10 \mathrm{~m}$ lineares em cada parcela, desde a primeira planta emergida até a estabilização do estande.

A uniformidade de distribuição de sementes foi obtida medindo-se o espaçamento entre 20 sementes, em cada unidade experimental. Após as leituras, os espaçamentos foram classificados em normais, duplos e falhos conforme metodologia proposta por Kurachi et al. (1989).

Realizou-se a mensuraçáo do estande inicial de plantas após a estabilizaçáo da emergência da cultura, contando-se as plantas existentes em cinco metros de cada linha de semeadura de cada unidade experimental, posteriormente extrapolou-se este resultado para o número de plantas por hectare.

No período de colheita do experimento foi coletado um total de dez espigas por linha de semeadura de cada unidade experimental. Nestas foram mensurados, manualmente, os seguintes componentes: número de fileiras por espiga, número de grãos por fileira e massa de mil grãos.

Quando a umidade de campo ficou próxima a 17\%, colheram-se manualmente as espigas das plantas ao longo de $5 \mathrm{~m}$ lineares, nas três linhas centrais de cada unidade experimental, posteriormente as mesmas foram trilhadas e pesadas em uma trilhadora estacionária da marca Maqtron, modelo B 380. O resultado foi extrapolado para a produtividade por hectare corrigindo-se a umidade dos grãos para $14 \%$.

Os dados foram inicialmente submetidos ao teste de Shapiro-Wilk a 5\% de significância, para determinar a normalidade dos mesmos, caso necessário, efetuou-se a transformação adequada para cada parâmetro avaliado. Visando verificar os efeitos dos fatores manejo de palhada de cobertura, mecanismos sulcadores, velocidades de operação e suas interaçôes efetuou-se análise da variância, por meio do teste "F". Havendo diferenças significativas, as médias foram comparadas pelo teste de Tukey, a $\mathrm{p} \leq 0,05$ de significância, utilizando o programa ASSISTAT 7.5 Beta desenvolvido por Silva e Azevedo (2002).

\section{RESULTADOS E DISCUSSÃO}

Os dados referentes aos espaçamentos aceitáveis, falhos e duplos (uniformidade de distribuição de sementes), apresentaram distribuiçáo tida como não normal pelo teste de Shapiro-Wilk a $\mathrm{p}<0,05$, com valores de 0,016; 0,005 e 0,041 , respectivamente. Os valores foram normalizados utilizando-se da transformação arco seno $(\mathrm{p} / 100)^{0,5}$, utilizada quando os dados são expressos em porcentagens ou proporçóes, sendo que o aumento de uma variável implica necessariamente na redução de outra. A anova foi realizada com os dados transformados e as tabelas de médias foram expressas com os dados normais a fim de melhor entendimento.
Não foram observadas variaçôes quanto à profundidade de semeadura e área de solo mobilizada para os diferentes tratamentos empregados no experimento (Tabela 1), bem como, não foi verificada interação entre os tratamentos.

Quanto maior a profundidade de deposição das sementes, maior será a exigência em energia para o processo de emergência, além de prejuízos causados por baixas temperaturas e baixos níveis de oxigênio; já quanto menor a profundidade, maior a suscetibilidade da semente a estresses hídricos (KoAKoski et al., 2007; Weirich Neto et al., 2007). No presente trabalho as profundidades de operaçáo ficaram entre 0,05 e $0,06 \mathrm{~m}$.

Quanto à área de solo mobilizada, a mesma tem grande relação com a profundidade de atuação dos mecanismos sulcadores. Porém, o volume de solo mobilizado não se relaciona com a quantidade e fracionamento da palhada depositada sobre o solo (Herzog et al., 2004). Observa-se pela tabela 1 que não fora observada influênciada palhada, dos mecanismos sulcadores e das velocidades de semeadura utilizadas sobre a área de solo mobilizada no momento da semeadura da cultura do milho.

O manejo de plantas apresentou influência sobre a percentagem de espaçamentos falhos, sendo que, a palhada dessecada apresentou os maiores percentuais $(11,7 \%)$ e a palha triturada os menores percentuais $(7,7 \%)$. Pinheiro Neto et al. (2008) trabalhando com diferentes mecanismos dosadores de sementes (disco horizontal e pneumático), velocidades de semeadura (disco horizontal: 4,74; 5,41; 6,47 e 7,24 $\mathrm{km} \mathrm{h}^{-1}$ e pneumática: 5,56; 8,04 e $10,21 \mathrm{~km} \mathrm{~h}^{-1}$ ) e condiçôes de cobertura do solo (vegetação espontânea, aveia dessecada e aveia dessecada + rolada), não encontraram efeitos das diferentes condiçóes de cobertura do solo sobre a porcentagem de espaçamentos falhos. No presente trabalho estas diferenças foram evidenciadas, sendo que a palha intacta apresentou elevação da porcentagem de espaçamentos falhos, devido a dificuldade de atuação dos mecanismos de abertura de sulco e de reposiçẫo de solo sobre a semente. Já quanto à velocidade de semeadura os mesmos autores observaram que, a elevação de velocidade de 5,56 para $10,21 \mathrm{~km} \mathrm{~h}^{-1}$ provocou um incremento do espaçamento falho de $17 \%$.

No presente trabalho a velocidade de operação do conjunto motomecanizado influenciou significativamente os espaçamentos falhos, duplos e aceitáveis (Tabela 1), sendo que a velocidade de $7,0 \mathrm{~km} \mathrm{~h}^{-1}$ apresentou elevaçáo de $63,5 \%$ dos espaçamentos falhos, $62,3 \%$ de espaçamentos duplos e consequente redução de $10,5 \%$ dos espaçamentos tidos como aceitáveis em comparação a velocidade de semeadura de $4,5 \mathrm{~km} \mathrm{~h}^{-1}$. Resultados semelhantes foram encontrados por (BRANQuinho et al., 2004; Mello et al., 2007; Dias et al., 2009; Liu et al., 2010). Embora se tenha observado diferenças na uniformidade de distribuição de sementes quando da elevação da velocidade de semeadura, as mesmas apresentaram espaçamentos aceitáveis na 
Tabela 1. Síntese da análise da variância e valores médios da profundidade de semeadura (PS), área de solo mobilizada (AM), espaçamento falho (EF), espaçamento duplo (ED), espaçamento aceitável (EA) e estande inicial de plantas (EI) em funçáo dos diferentes manejos de palhada, mecanismos sulcadores e velocidades de semeadura da cultura do milho

\begin{tabular}{|c|c|c|c|c|c|c|c|}
\hline FV & & PS (cm) & $\operatorname{AM}\left(\mathrm{cm}^{2}\right)$ & EF (\%) & ED (\%) & EA (\%) & El (plantas ha ${ }^{-1}$ ) \\
\hline \multicolumn{8}{|l|}{ Man. (M) } \\
\hline Dessecada & & 5,61 & 38,77 & $11,68 \mathrm{a}$ & 8,55 & 79,77 & $70234,59 a b$ \\
\hline Gradeada & & 5,46 & 34,80 & $9,37 a b$ & 10,03 & 80,59 & $71365,48 \mathrm{ab}$ \\
\hline Rolada & & 5,29 & 33,45 & $9,37 \mathrm{ab}$ & 9,37 & 81,25 & $69847,70 \mathrm{~b}$ \\
\hline Triturada & & 5,65 & 38,02 & $7,73 \mathrm{~b}$ & 8,72 & 83,55 & $72764,22 \mathrm{a}$ \\
\hline \multicolumn{8}{|l|}{ Sulc. (S) } \\
\hline Disco & & 5,42 & 36,16 & 9,70 & 9,37 & 80,92 & 71142,27 \\
\hline Haste & & 5,58 & 36,36 & 9,37 & 8,96 & 81,66 & 70963,71 \\
\hline \multicolumn{8}{|l|}{ Vel. (V) } \\
\hline $4,5 \mathrm{~km} \mathrm{~h}^{-1}$ & & 5,61 & 35,94 & $7,24 \mathrm{~b}$ & $6,99 \mathrm{~b}$ & $85,77 a$ & 71871,41 \\
\hline \multirow[t]{2}{*}{$7,0 \mathrm{~km} \mathrm{~h}^{-1}$} & & 5,40 & 36,58 & $11,84 \mathrm{a}$ & $11,35 \mathrm{a}$ & $76,81 \mathrm{~b}$ & 70234,59 \\
\hline & GL & \multicolumn{6}{|c|}{ Quadrado médio } \\
\hline M & 3 & $0,4369^{\text {ns }}$ & $103,6069^{\text {ns }}$ & $42,1283^{*}$ & $7,3219^{\text {ns }}$ & $42,2366^{\mathrm{ns}}$ & $27458559,6092^{*}$ \\
\hline Resíduo a & 9 & 0,9809 & 92,1439 & 9,7145 & 9,7265 & 18,8639 & 5569162,8639 \\
\hline S & 1 & $0,4192^{\text {ns }}$ & $0,6136^{\text {ns }}$ & $1,7313^{\text {ns }}$ & $2,7051^{\mathrm{ns}}$ & $8,7647^{\text {ns }}$ & $510163,7763^{\text {ns }}$ \\
\hline$M * S$ & 3 & $0,2640^{\text {ns }}$ & $15,1091^{\mathrm{ns}}$ & $24,2382^{\text {ns }}$ & $7,6105^{\text {ns }}$ & $56,6640^{\text {ns }}$ & $1426552,7429^{\text {ns }}$ \\
\hline Resíduo b & 12 & 0,3141 & 40,6330 & 31,0191 & 12,4437 & 59,4052 & 4277252,2312 \\
\hline V & 1 & $0,6847^{\text {ns }}$ & $6,6736^{\text {ns }}$ & $339,3351^{* *}$ & $303,9518^{* *}$ & $1285,6004^{* *}$ & $42867104,5535^{\mathrm{ns}}$ \\
\hline$M^{*} V$ & 3 & $0,4727^{\text {ns }}$ & $64,0995^{\mathrm{ns}}$ & $28,2779^{\text {ns }}$ & $6,8530^{\text {ns }}$ & $21,7495^{\mathrm{ns}}$ & $4671683,3353^{\text {ns }}$ \\
\hline $\mathrm{S} * \mathrm{~V}$ & 1 & $0,1008^{\text {ns }}$ & $33,4469^{\text {ns }}$ & $43,2825^{\text {ns }}$ & $78,8825^{\mathrm{ns}}$ & $39,0278^{\text {ns }}$ & $18365553,1051^{\mathrm{ns}}$ \\
\hline$M^{*} S^{*} V$ & 3 & $0,3258^{\text {ns }}$ & $26,2098^{\text {ns }}$ & $8,0794^{\text {ns }}$ & $11,0730^{\text {ns }}$ & $7,6105^{\text {ns }}$ & $5413303,1308^{\text {ns }}$ \\
\hline Resíduo c & 24 & 0,3312 & 77,5072 & 20,4870 & 24,8514 & 49,8110 & 13315955,8125 \\
\hline C.V. (M) & - & 18,0 & 26,5 & 32,7 & 34,0 & 5,3 & 3,3 \\
\hline C.V. (S) & - & 10,2 & 17,6 & 58,4 & 38,5 & 9,5 & 2,9 \\
\hline C.V. (V) & - & 10,5 & 24,3 & 47,4 & 54,4 & 8,7 & 5,1 \\
\hline
\end{tabular}

Médias seguidas de mesma letra na coluna năo diferem significativamente. ${ }^{*}$ significativo ao nível de $\mathrm{p}<0,01$; ${ }^{*}$ significativo ao nível de $0,01 \leq \mathrm{p}<0,05$; ns: năo significativo. C.V.: coeficiente de variaçăo; GL: grau de liberdade.

faixa de $75 \%$ a $90 \%$, apresentando um bom desempenho de semeadura.

Quanto ao estande de plantas, pode-se observar que o manejo de palhada triturada proporcionou elevação de $4,2 \%$ no estande de plantas $(72764,2$ plantas $\left.\mathrm{ha}^{-1}\right)$ em comparaçáo a semeadura sobre palhada rolada $\left(69847,7\right.$ plantas ha $\left.{ }^{-1}\right)$. Bortoluzzi e Eltz (2000) avaliando o efeito do manejo de palhada de aveia sobre a emergência da soja, concluíram que, a manutenção de palhada sobre o solo propicia melhor emergência e velocidade de emergência da cultura em comparaçáo a retirada de palha, entretanto, os diferentes manejos da palha não propiciam diferenças de emergência e consequentemente de estande de plantas.

Observa-se a partir da tabela 1 que não ocorreram diferenças significativas no estande de plantas entre as velocidades de 4,5 e 7,0 $\mathrm{km} \mathrm{h}^{-1} \mathrm{e}$ da utilização de mecanismos sulcadores do tipo haste e disco. Estes resultados discordam dos obtidos por MaHL et al. (2004) e Bitencourt et al. (2008) que encontraram redução da população de plantas com a elevação da velocidade de 4,0 para $8,0 \mathrm{~km} \mathrm{~h}^{-1}$. Do mesmo modo, KaneKo et al. (2010), observaram maior estande de plantas de feijāo quando da utilização do mecanismo de abertura de sulco tipo haste em comparaçáo ao mecanismo tipo disco duplo desencontrado. Este maior estande de plantas não foi observado no presente trabalho.

A marcha de emergência da cultura do milho apresentou elevaçáo a partir do quinto dia pós-semeadura e estabilizou ao décimo terceiro dia (Figura 3). Os fatores velocidades de semeadura (Figura $3 \mathrm{~b}$ ) e mecanismos sulcadores (Figura 3c) náo afetaram o comportamento da marcha de emergência da cultura, porém, quando da inserção dos diferentes manejos de cobertura (Figura 3a), pode-se verificar que a cultura semeada pós-manejo de palhada com triturador tende a apresentar uma emergência de plântulas acelerada do quinto ao sétimo dia pós-semeadura, sendo que, ao sexto dia após a semeadura verificou-se uma emergência de plântulas de 50,3\%, contra $12,2 \%, 5,8$ e 5,2\% para os tratamentos de palha gradeada, rolada e dessecada, respectivamente. Isto se deve a melhor qualidade de semeadura observada neste manejo, uma vez que, observou-se melhor uniformidade da palhada e maior fracionamento da mesma, garantindo melhor desempenho do conjunto mecanizado.

Em experimento avaliando os manejos de cobertura com rolo-faca e triturador de palhas e pressôes de inflação do pneu da semeadora-adubadora, no estabelecimento da cultura do milho, Cortez et al. (2009) concluíram que, os diferentes manejos de palhada não influenciaram no 

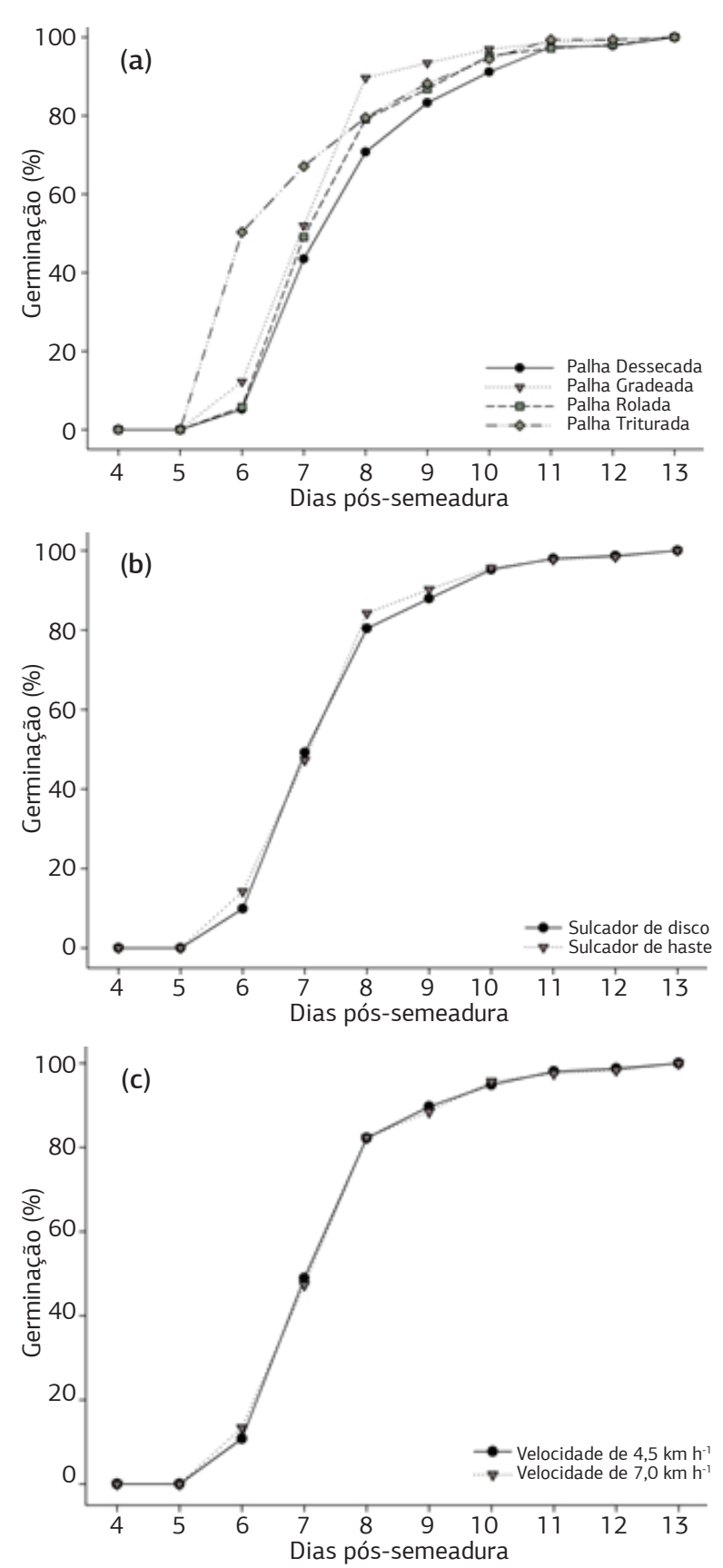

Figura 3. Marcha de emergência da cultura do milho sobre diferentes manejos de cobertura (a), mecanismos sulcadores (b) e velocidades de semeadura (c).

número de dias para a emergência, resultando em valores médios de quatro dias para a emergência. Os resultados encontrados pelos autores discordam dos observados no presente trabalho, uma vez que, houve diferenças significativas para os diferentes manejos e necessitou-se de aproximadamente sete dias para a obtenção de 50\% de emergência.

Quanto a marcha de emergência da cultura em função dos diferentes mecanismos sulcadores, pode-se verificar que a mesma teve comportamento similar tanto quando da inserção do mecanismo disco, como quando da inserção do mecanismo sulcador tipo haste. Observa-se ainda que, ambos os mecanismos sulcadores proporcionaram aproximadamente $50 \%$ da germinação da cultura ao sétimo dia pós-semeadura. Reis et al. (2006) trabalhando com a utilização de diferentes mecanismos sulcadores (haste e disco) e rodas compactadoras (borracha e lisa) sobre três teores de agua do solo $\left(0,22 ; 0,28 ; \mathrm{e} 0,34 \mathrm{~kg} \mathrm{~kg}^{-1}\right)$, não verificaram diferenças significativas quanto a velocidade de emergência da cultura quando da inserção de diferentes mecanismos sulcadores.

A tabela 2 apresenta os valores médios dos componentes de produtividade da cultura do milho sobre a influência dos diferentes tratamentos empregados, onde verifica-se que os diferentes tratamentos náo tiveram influência significativa sobre nenhum dos parâmetros avaliados. Verifica-se ainda, interaçấo significativa entre os manejos de cobertura e sulcadores e entre sulcadores e velocidades para a produtividade de grãos, no entanto, esta significância náo foi verificada para os desdobramentos das interaçôes pelo teste de Tukey a $\mathrm{p}<0,05$ de probabilidade.

Os resultados obtidos corroboram com Mello et al. (2007) que ao avaliarem dois híbridos diferentes (DKB 390 e DKB 435), em três velocidades de deslocamento $\left(5,4 ; 6,8\right.$ e $\left.9,8 \mathrm{~km} \mathrm{~h}^{-1}\right)$, não encontraram diferenças significativas entre as velocidades avaliadas para a variável número de fileiras por espiga e grãos por fileira. Esses resultados se justificam, uma vez que, segundo MagalHấes e Durâes (2006), a definição do número de fileiras por espiga ocorre no estádio V8 e a definição deste componente de produtividade se deve em grande parte ao fator genético. Devido à baixa plasticidade da cultura do milho, os componentes de produtividade sofrem pouca variação com os diferentes tratamentos empregados.

Mello et al. (2007) avaliando o desenvolvimento e os componentes de produção de dois híbridos de milho (DKB 390 e DKB 435) em função de três velocidades de semeadura $\left(5,4 ; 6,8\right.$ e 9,8 $\left.\mathrm{km} \mathrm{h}^{-1}\right)$, verificaram que a elevação da velocidade de semeadura não proporcionou diferenças significativas quanto ao número de grãos por fileira, corroborando com o presente trabalho e com trabalho desenvolvido por (GARCIA et al., 2006).

GARCIA et al. (2006), avaliando o desempenho de uma semeadora-adubadora nas velocidades de 3,0 a 9,0 $\mathrm{km} \mathrm{h}^{-1}$ e Bitencourt et al. (2008) trabalhando nas velocidades de 5,0; 6,0; 7,0 e $8,0 \mathrm{~km} \mathrm{~h}^{-1}$, não observaram diferenças significativas para a variável peso de mil grãos quando da elevação da velocidade de semeadura, corroborando com o presente trabalho.

Por outro lado, Mello et al. (2007) ao avaliarem dois diferentes híbridos (DKB 390 e DKB 435) e três velocidade de deslocamento $\left(5,4 ; 6,8\right.$ e 9,8 $\left.\mathrm{km} \mathrm{h}^{-1}\right)$, encontraram diferenças significativas entre as velocidades avaliadas para a variável massa de mil grãos. Segundo os autores, a massa de grãos na espiga é a variável que, isoladamente, melhor representa o potencial produtivo de um híbrido. 
Tabela 2. Síntese da análise da variância e valores médios do número de fileiras por espiga (NFE), número de grãos por fileira (NGF), massa de mil grãos (MMG) e produtividade media da cultura (PROD) em função de diferentes manejos de palhada, mecanismo sulcadores e velocidades de semeadura da cultura do milho

\begin{tabular}{|c|c|c|c|c|c|}
\hline FV & & NFE & NGF & MMG (g) & PROD (kg ha-1) \\
\hline \multicolumn{6}{|l|}{ Manejo (M) } \\
\hline Dessecada & & 12,98 & 78,09 & 358,92 & 11180,39 \\
\hline Gradeada & & 13,04 & 76,32 & 372,85 & 11176,11 \\
\hline Rolada & & 12,94 & 77,29 & 369,36 & 11506,57 \\
\hline Triturada & & 13,00 & 76,33 & 374,55 & 11581,56 \\
\hline \multicolumn{6}{|l|}{ Sulcador (S) } \\
\hline Disco & & 13,04 & 76,88 & 367,49 & 11296,16 \\
\hline Haste & & 12,94 & 77,14 & 370,35 & 11426,16 \\
\hline \multicolumn{6}{|l|}{ Velocidade (V) } \\
\hline $4,5 \mathrm{~km} \mathrm{~h}^{-1}$ & & 13,01 & 77,11 & 370,33 & 11467,22 \\
\hline \multirow[t]{2}{*}{$7,0 \mathrm{~km} \mathrm{~h}^{-1}$} & & 12,97 & 76,91 & 367,50 & 11255,09 \\
\hline & GL & & Idrado mé & & \\
\hline M & 3 & $0,0325^{\text {ns }}$ & $11,6630^{\text {ns }}$ & $786,1518^{\text {ns }}$ & $728759,7272^{\text {ns }}$ \\
\hline Resíduo a & 9 & 0,0455 & 3,9927 & 418,1376 & 1014316,3042 \\
\hline S & 1 & $0,1406^{\text {ns }}$ & $1,0634^{\text {ns }}$ & $130,1042^{\text {ns }}$ & $270377,6404^{\text {ns }}$ \\
\hline$M * S$ & 3 & $0,0338^{\text {ns }}$ & $1,3831^{\text {ns }}$ & $650,0176^{\text {ns }}$ & $108936,2016^{*}$ \\
\hline Resíduo b & 12 & 0,1308 & 3,9842 & 870,6537 & 1705732,3039 \\
\hline V & 1 & $0,0351^{\text {ns }}$ & $0,6103^{\text {ns }}$ & $127,9907^{\text {ns }}$ & $720002,3123^{\mathrm{ns}}$ \\
\hline$M^{*} V$ & 3 & $0,0638^{\text {ns }}$ & $7,9391^{\text {ns }}$ & $208,7806^{\text {ns }}$ & $923709,4525^{\text {ns }}$ \\
\hline$S^{*} V$ & 1 & $0,1406^{\text {ns }}$ & $1,8056^{\mathrm{ns}}$ & $101,5000^{\text {ns }}$ & $119,9736^{*}$ \\
\hline$M * S^{*} V$ & 3 & $0,0651^{\text {ns }}$ & $2,0107^{\text {ns }}$ & $292,8185^{\text {ns }}$ & $1284503,8354^{\text {ns }}$ \\
\hline Resíduo c & 24 & 0,1770 & 4,0052 & 274,8615 & 1320983,0730 \\
\hline C.V. (M) & - & 1,64 & 2,59 & 5,54 & 8,86 \\
\hline C.V. (S) & - & 2,78 & 2,59 & 8,00 & 11,50 \\
\hline C.V. (V) & - & 3,24 & 2,60 & 4,49 & 10,12 \\
\hline
\end{tabular}

Médias seguidas de mesma letra na coluna năo diferem significativamente. ${ }^{*}$ significativo ao nível de $\mathrm{p}<0,01$; ${ }^{*}$ significativo ao nível de $0,01 \leq \mathrm{p}<0,05$; ns: năo significativo. C.V.: coeficiente de variaçăo; GL: grau de liberdade.

BranQuinho et al. (2004), avaliando a influência de diferentes manejos da palhada de aveia preta sobre a produtividade média da cultura da soja, observaram que, a produtividade de grãos de soja não foi afetado pelo sistema de manejo de palhada, corroborando com o presente trabalho.

Trabalhando-se com diferentes culturas de cobertura e manejo da palhada observa-se que, a inserção do manejo de palhada, no caso o triturador, proporciona menor estande final de plantas e consequentemente menor produtividade final de culturas, devido às maiores variaçôes de temperatura, bem como as altas variaçôes do teor de água do solo, proporcionada pela inserção do manejo mecânico (Ferrari Neto et al., 2011). Já Muraishi et al. (2005), trabalhando com manejo de cobertura e posterior semeadura de milho e soja, observaram que, a produtividade média de ambas as culturas se elevaram quando da inserção do manejo mecânico (triturador), principalmente devido ao fato de uniformizar a distribuição de palhada e manter uma população de plantas ideal. Nem a mitigação de produtividade observada por FerRARi Neto et al. (2011), nem a elevação de produtividade verificada por Muraishi et al. (2005) foram encontradas no presente trabalho, ocorreu apenas a não influência do tratamento manejo de palhada sobre a produtividade média de grãos.
Trabalhando com velocidades de semeadura de 3,0 a $9,0 \mathrm{~km} \mathrm{~h}^{-1}$ em quatro condiçóes de campo, Garcia et al. (2006), concluíram que a velocidade de semeadura só afeta a produtividade quando há alteração do estande no momento da colheita, sendo que, a alteração da uniformidade de distribuição de sementes por meio do aumento da velocidade não resultou em diferenças significativas para este parâmetro. Afirmativa esta que corrobora com os resultados do presente trabalho evidenciando que a uniformidade de distribuição de sementes não está intimamente ligada a produção de grãos na área.

MaHL et al. (2008) observaram que, o incremento de velocidade de 4,4 a $9,8 \mathrm{~km} \mathrm{~h}^{-1}$ não influenciou significativamente a produtividade da cultura do milho. Os autores justificam esse resultado ao fato deste aumento de velocidade também não ter influenciado o estande de plantas e a sobrevivência das mesmas ao longo do ciclo da cultura, resultado este que se assemelha ao presente trabalho.

\section{CONCLUSÃO}

Pelas condiçôes de campo desse trabalho, o manejo da palha, velocidade ou tipo de sulcador empregado na semeadora não influenciaram significativamente a 
produtividade média da cultura do milho. No entanto, as diferentes velocidades de semeadura influenciaram significativamente a uniformidade de distribuição de sementes, levando a espaçamentos falhos, ao posicionamento de sementes duplas e reduzindo os tidos como aceitáveis.

\section{AGRADECIMENTOS}

Os autores agradecem a CAPES, CNPq, IAPAR e a UTFPR, pelo apoio financeiro e de infraestrutura para desenvolvimento do trabalho.

\section{REFERÊNCIAS}

ANDRADE, R.S.; STONE, L.F.; SILVEIRA, P.M. Culturas de cobertura e qualidade física de um Latossolo em plantio direto. Revista Brasileira de Engenharia Agrícola e Ambiental, v.13, p.411418, 2009.

BITENCOURT, R.; TAVARES, C.A.; FORALOSSO, A.A.; VIGANÓ, J.P.; OLIVEIRA, L.G.; DUARTH, M.; PRIMO, M.A.; SONCELA, R.; SILVA, S.L.; SILVA, T.R.B. Influência da velocidade de deslocamento da semeadora, com haste sulcadoras na produtividade do milho. Cultivando o saber, v.1, p.24-33, 2008.

BORTOLUZZI, E.C.; ELTZ, F.L.F. Efeito do manejo mecânico da palhada de aveia preta sobre a cobertura, temperatura, teor de água no solo e emergência da soja em sistema plantio direto. Revista Brasileira de Ciência do Solo, v.24, p.449-457, 2000.

BRANQUINHO, K.B.; FURLANI, C.E.A.; LOPES, A.; SILVA, R.P.; GROTTA, D.C.C.; BORSATTO, E.A. Desempenho de uma semeadora-adubadora direta, em funçáo da velocidade de deslocamento e do tipo de manejo da biomassa da cultura de cobertura do solo. Engenharia Agrícola, v.24, p.374-380, 2004.

CARNEIRO, M.A.C.; SOUZA, E.D.; REIS, E.F.; PEREIRA, H.S.; AZEVEDO, W.R. Atributos físicos, químicos e biológicos de solo de cerrado sob diferentes sistemas de uso e manejo. Revista Brasileira de Ciência do Solo, v.33, p.147-157, 2009.

COMISSÃO DE QUÍMICA E FERTILIDADE DO SOLO - CQFS. Manual de adubaçáo e calagem para os estados do Rio Grande do Sul e de Santa Catarina. Porto Alegre, 2004. 394p.

CORTEZ, J.W.; FURLANI, C.E.A.; VIGNA, G.P.; BORSATTO, E.A.; SILVA, R.P. Desempenho do trator agrícola no manejo da cultura de cobertura e pressão de inflação do pneu da semeadora. Engenharia Agrícola, v.29, p.72-80, 2009.

DIAS, V.O.; ALONÇO, A.S.; BAUMHARDT, U.B.; BONOTTO, G.J. Distribuição de sementes de milho e soja em funçáo da velocidade e densidade de semeadura. Ciência Rural, v.39, p.1721-1728, 2009.

FALLEIRO, R.M.; SOUZA, C.M.; SILVA, C.S.W.; SEDIYAMA, C.S.; SILVA, A.A.; FAGUNDES, J.L. Influência dos sistemas de preparo nas propriedades químicas e físicas do solo. Revista Brasileira de Ciência do Solo, v.27, p.1097-1104, 2003.
FERRARI NETO, J.; CRUSCIOL, C.A.C.; SORATTO, R.P.; COSTA, C.H.M. Plantas de cobertura, manejo da palhada e produtividade da mamoneira no sistema plantio direto. Revista Ciência Agronômica, v.42, p.978-985, 2011.

FURLANI, C.E.A.; CORTEZ, J.W.; SILVA, R.P.; GROTTA, D.C.C. Cultura do milho em diferentes manejos de plantas de cobertura do solo em plantio direto. Revista de Biologia e Ciências da Terra, v.7, p.161-167, 2007.

GARCIA, L.C.; JASPER, R.; JASPER, M.; FORNARI, A.J.; BLUM, J. Influência da velocidade de deslocamento na semeadura do milho. Engenharia Agrícola, v.26, p.520-527, 2006.

GARCIA, R.F.; DO VALE, W.G.; DE OLIVEIRA, M.T.R.; PEREIRA, É.M.; AMIM, R.T.; BRAGA, T.C. Influência da velocidade de deslocamento no desempenho de uma semeadoraadubadora de precisão no Norte Fluminense. Acta Scientiarum Agronomy, v.33, p.417-422, 2011.

GERMINO, R.; BENEZ, H.S. Ensaio comparativo em dois modelos de hastes sulcadoras para semeadoras-adubadoras de plantio direto. Engenharia Agrícola, v.21, p.85-92, 2006.

HERZOG, R.L.S.; LEVIEN, R.; TREIN, C.R. Produtividade de soja em semeadura direta influenciada por profundidade do sulcador de adubo e doses de resíduo em sistema irrigado e não irrigado. Engenharia Agrícola, v.24, p.771-780, 2004.

KANEKO, F.H.; ARF, O.; GITTI, D.C.; ARF, M.V.; FERREIRA, J.P.; BUZETTI, S. Mecanismos de abertura de sulcos, inoculação e adubação nitrogenada em fei joeiro em sistema plantio direto. Bragantia, v.69, p.125-133, 2010.

KOAKOSKI, A.; SOUZA, C.M.A.; RAFULL, L.Z.L.; SOUZA, L.C.F.; REIS, E.F. Desempenho de semeadora-adubadora utilizando-se dois mecanismos rompedores e três pressôes da roda compactadora. Pesquisa Agropecuária Brasileira, v.42, p.725-731, 2007.

KURACHI, S.A.H.; COSTA, J.A.S.; BERNARDI, J.A.; COELHO, J.L.D.; SILVEIRA, G.M. Avaliação tecnológica de semeadoras e/ou adubadoras: tratamento de dados de ensaio e regularidade de distribuição longitudinal de sementes. Bragantia, v.48, p.249-262, 1989.

LIU, J.; CHEN, Y.; KUSHWAHA, R.L. Effect of tillage speed and straw length on soil and straw movement by a sweep. Soil and Tillage Research, v.109, p.9-17, 2010.

LUCIANO, R.V.; BERTOL, I.; BARBOSA, F.T.; KURTZ, C.; FAYAD, J.A. Propriedades físicas e carbono orgânico do solo sob plantio direto comparados à mata natural, num Cambissolo Háplico. Revista de Ciências Agroveterinárias, v.9, p.9-19, 2010.

MAGALHÂES, P.C.; DURÃES, F.O.M. Fisiologia da Produção de Milho. Circular Técnica. Ministério da Agricultura Pecuária e Abastecimento. Sete Lagoas, MG Dezembro, 2006.

MAHL, D.; FURLANI, C.E.A.; GAMERO, C.A. Efficiency of pneumatic and horizontal perforated disk meter mechanism in corn no-tillage seeders in soil with different mobilization reports. Engenharia Agrícola, v.28, p.535-542, 2008. 
MAHL, D.; GAMERO, C.A.; BENEZ, S.H.; FURLANI, C.E.A.; SILVA, A.R.B. Demanda energética e eficiência da distribuição de sementes de milho sob variação de velocidade e condição de solo. Engenharia Agrícola, v.24, p.150-157, 2004.

MELLO, A.J.R.; FURLANI, C.E.A.; SILVA, R.P.; LOPES, A.; BORSATTO, E.A. Produtividade de híbridos de milho em funçáo da velocidade de semeadura. Engenharia Agrícola, v.27, p.479-486, 2007.

MURAISHI, C.T.; LEAL, A.J.F.; LAZARINI, E.; RODRIGUES, L.R.; JUNIOR, F.G.G. Manejo de espécies vegetais de cobertura de solo e produtividade do milho e da soja em semeadura direta. Acta Scientiarum Agronomy, v.27, p.199-207, 2005.

PINHEIRO NETO, R.; BRACCINI, A.L.; SCAPIM, C.A.; BORTOLOTTO, V.C.; PINHEIRO, A.C. Desempenho de mecanismos dosadores de sementes em diferentes velocidades e condiçôes de cobertura do solo. Acta Scientiarum Agronomy, v.30, p.611-617, 2008.
REIS, E.F.; SCHAEFER, C.E.G.R.; FERNANDES, H.C.; NAIME, J.M.; ARAÚJO, E.F. Densidade do solo no ambiente solo-semente e velocidade de emergência em sistema de semeadura de milho. Revista Brasileira de Ciência do Solo, v.30, p.777-786, 2006.

SILVA, F.A.S.; AZEVEDO, C.A.V. Versão do programa computacional assistat para o sistema operacional Windows. Revista Brasileira de Produtos Agroindustriais, v.4, p.71-78, 2002.

SIQUEIRA, R.; CASÃO JÚNIOR, R. Trabalhador no cultivo de grãos e oleaginosas: Máquinas para manejo de coberturas e semeadura no sistema de plantio direto. Coleçáo SENAR. Curitiba. p.26-28, 2004.

WEIRICH NETO, P.H.; SCHIMANDEIRO, A.; GIMENEZ, L.M.; COLET, M.J.; GARBUIO, P.W. Profundidade de deposição de semente de milho na região dos campos gerais, Paraná. Engenharia Agrícola, v.27, p.782-786, 2007. 